\title{
OPEN Effects of water and nitrogen coupling on the photosynthetic characteristics, yield, and quality of Isatis indigotica
}

\author{
Yucai Wang ${ }^{1 凶}$, Xiucheng He ${ }^{1}$, Fuqiang $\mathrm{Li}^{1}$, Haoliang Deng ${ }^{2}$, Zeyi Wang ${ }^{1}$, Caixia Huang ${ }^{1}$, \\ Yi Han ${ }^{1}$, Yuchun $\mathrm{Ba}^{3}$, Lian Lei ${ }^{3}$ \& Changlong Zhang ${ }^{3}$
}

Isatis indigotica is a commercial medicinal crop that is widely cultivated with high water and nutrient application, in the arid areas of northwest China. Rational irrigation and nitrogen application are key factors for successful crop management. The objective of this study was to determine the effect of water and nitrogen coupling on the photosynthetic characteristics, yield, and quality of Isatis indigotica produced in northwestern China. Field trials were conducted for 2 consecutive years at an irrigation test station. Data on photosynthetic parameters, yield, and quality were collected from individual Isatis indigotica for each treatment during 2018-2019. The application of nitrogen significantly increased photosynthetic rates and yield under the same irrigation conditions. However, the yields were reduced in the excess water treatments (W3N1 and W3N2) and in the excess nitrogen treatments (W1N3, W2N3, and W3N3) in contrast to the optimum W2N2 treatment. Moreover, the quality indicators of the W2N2 treatment decreased compared with CK, which was due to water stress and more photoassimilates being available to the roots, but the effective quality index value could be effectively improved by greatly increasing the yield.

In the oasis region of Hexi, China, agricultural development is limited by water shortages and the excessive application of nitrogen fertilizer. The major focus of research is determining ways to improve water use efficiency and to reduce nitrogen application. Two essential factors for crop growth are water and fertilizer application. Rational irrigation and fertilization can effectively improve crop yield. The main problem facing modern agriculture is how to promote fertilizer with water and transfer water with fertilizer ${ }^{1}$. Reasonable water-nitrogen coupling optimization models have received increasing attention from researchers. Water is the medium through which soil nutrients are effectively absorbed by plants, improving the efficiency of nitrogen utilization. However, excessive water application will lead to leaching and the loss of nitrogen, while excessive nitrogen application will lead to non-point source pollution ${ }^{2}$.

At present, an increasing number of studies have focused on the effects of coupled water and nitrogen application on crops. For example, Liu et al. ${ }^{3}$, Li et al. ${ }^{4}$, Sui et al. ${ }^{5}$, Fiasconaro et al. ${ }^{6}$, and Gholamhoseini et al. ${ }^{7}$ studied the effects of the coupling of water and nitrogen on the yield and quality of rice, tomato, cotton, alfalfa, and corn, respectively. The synergistic effect of water and nitrogen can save water, increase yield, and improve crop quality effectively. The yield and water use efficiency of Isatis indigotica were not high due to flood irrigation. Moreover, as growers seek to increase yields, the phenomenon of excessive nitrogen application is very common ${ }^{8}$.

Scholars have studied the effect of water on the yield and quality of Isatis indigotica from the aspects of water-saving irrigation systems ${ }^{9}$ and water stress ${ }^{10}$. However, no research is currently available on the influence of water and nitrogen fertilizer on photosynthesis, yield, and quality. Local farmers apply fertilizers and irrigate relying only on empirical observations, resulting in low-efficiency water and fertilizer utilization. Therefore, the aim of this research was to study the effect of water and nitrogen coupling on the photosynthesis, yield, and quality of Isatis indigotica.

${ }^{1}$ College of Water Conservancy and Hydropower Engineering, Gansu Agricultural University, 1 Yingmen Village, Lanzhou 730000, Gansu Province, China. ${ }^{2}$ College of Civil Engineering, Hexi University, Zhangye 734000, China. ${ }^{3}$ Yimin Irrigation Experimental Station, Minle County, Zhangye 734500, China. ${ }^{\square}$ email: wangyucai118@163.com 


\begin{tabular}{|c|c|c|c|}
\hline Treatment & Serial number & $\mathrm{N}$ application/( $\left.\mathrm{kg} \mathrm{hm}^{-2}\right)$ & Field water capacity (\%) \\
\hline Low water, low nitrogen & W1N1 & 150 & $60-70$ \\
\hline Low water, medium nitrogen & W1N2 & 200 & $60-70$ \\
\hline Low water, high nitrogen & W1N3 & 250 & $60-70$ \\
\hline Medium water, low nitrogen & W2N1 & 150 & $70-80$ \\
\hline Medium water, medium nitrogen & W2N2 & 200 & $70-80$ \\
\hline Medium water, high nitrogen & W2N3 & 250 & $70-80$ \\
\hline High water, low nitrogen & W3N1 & 150 & $80-90$ \\
\hline High water, medium nitrogen & W3N2 & 200 & $80-90$ \\
\hline High water, high nitrogen & W3N3 & 250 & $80-90$ \\
\hline Control treatment & WON0 & 0 & 0 \\
\hline
\end{tabular}

Table 1. Experimental treatment of water-nitrogen coupling in Isatis indigotica.

\begin{abstract}
Materials and methods
Location. The experiments were carried out at the Yimin Irrigation Pilot Station (Gansu, China; $100^{\circ} 43^{\prime} \mathrm{E}$, $38^{\circ} 39^{\prime} \mathrm{N}$ ) in the middle reaches of the Flood River Irrigation District, Minle County, Gansu Province from May to October in 2018 and 2019. The Yimin Irrigation Experimental Station and Flood River Administration Office, Minle County, China provided permission to collect Isatis indigotica. The experimental zone has a continental desert steppe climate, with a dry climate, abundant heat, abundant light, and little rain; the altitude is about $1970 \mathrm{~m}$. According to the yearly precipitation data, the average annual precipitation in this area is $215 \mathrm{~mm}$ with little precipitation and large variation. The contradiction between supply and demand is prominent, and drought is frequent. The soil is light loam with a $\mathrm{pH}$ value of 7.22 , the field water-holding capacity of tillage layer soil is $24 \%$, the soil bulk density is $1.4 \mathrm{~g} \mathrm{~cm}^{-3}$, the groundwater level is low, and the area does not exhibit salinization or alkalization.
\end{abstract}

Test materials and cultivation methods. Isatis indigotica seeds were cultivated and provided in the Department of Chinese herbal medicine, Gansu Agricultural University. The seed purity was 96\%, the weight per 1000 seeds was $9.873 \mathrm{~g}$, the germination rate was $87.6 \%$, and the germination potential was $46.4 \%$. The seeds were sown on May 3 and harvested on October 13. The seeds were sown at $30.0 \mathrm{~kg} \mathrm{hm}^{-2}$ and the planting density was 800,000 plants $\mathrm{hm}^{-2}$. The plant spacing of Isatis indigotica was about $20 \mathrm{~cm}$, and the row spacing was about $30 \mathrm{~cm}$. Before sowing, the experimental zone was ploughed for $30 \mathrm{~cm}$ to remove weeds manually. Moreover, $350 \mathrm{~kg} \mathrm{hm}^{-2}$ calcium superphosphate $\left(12 \% \mathrm{P}_{2} \mathrm{O}_{5}, 10 \% \mathrm{~S}\right.$, and $\left.16 \% \mathrm{Ca}\right)$ and $200 \mathrm{~kg} \mathrm{hm}^{-2}$ source potassium $(25 \%$ $\mathrm{K}_{2} \mathrm{O}$ ) were applied. Each experimental plot was separated by a film with a width of $60 \mathrm{~cm}$ to prevent underground water seepage.

Experimental design. The growth of Isatis indigotica is divided into four stages based on the growth characteristics: the seedling stage, vegetative stage, fleshy root growth stage, and fleshy root maturity. Three irrigation treatments were set in the field experiment. Treatments W1, W2, and W3 were $60-70 \%$ of field water capacity, $70-80 \%$ of field water capacity, and $80-90 \%$ of field water capacity, respectively. There were three nitrogen treatments: N1: $150 \mathrm{~kg} \mathrm{hm}^{-2}, \mathrm{~N} 2: 200 \mathrm{~kg} \mathrm{hm}^{-2}$, and N3: $250 \mathrm{~kg} \mathrm{hm}^{-2}$. There were 10 water control treatments, of which CK was the control treatment. Each treatment was repeated three times, with a total of 30 plots. The area of each plot was $36 \mathrm{~m}^{2}(9 \mathrm{~m} \times 4 \mathrm{~m})$. The method of irrigation was drip irrigation under mulch. The specific experimental design is presented in Table 1. All the experiments on plants were carried out in accordance with guidelines of Gansu Agricultural University.

Photosynthetic characteristics. Photosynthesis was measured using a Li-6400 portable photosynthesis system (Zhangye, Gansu, China) during the period of 9:30-10:30 a.m. on May 15, June 1, June 20, July 10, and July 25 in 2018 and 2019. The physiological parameters of net photosynthetic rate (Pn), stomatal conductance $(\mathrm{Gs})$, transpiration rate ( $\mathrm{Tr})$, and intercellular $\mathrm{CO}_{2}$ concentration $(\mathrm{Ci})$ were measured in situ for the seventh or eighth leaf that was fully expanded ${ }^{11}$ (counted back from the apex of new shoots). In each treatment, for each sampled plant, 3-4 sunlit healthy leaves were randomly selected from different parts of the plant and labeled; each leaf was measured once, in triplicate for each treatment. The average value of each treatment was calculated.

Yield and water use efficiency. At harvest time, the yield of each plot was weighed and counted separately, and the yield of each treatment was the average of three replicates. Water use efficiency (WUE) was calculated as follows:

$$
W U E=Y / E T_{a},
$$

where WUE is the water use efficiency $\left(\mathrm{kg} \mathrm{hm}^{-2} \mathrm{~mm}\right), Y$ is the yield per unit area of Isatis indigotica $\left(\mathrm{kg} \mathrm{hm}^{-2}\right.$ $\mathrm{mm}$ ), and $E T_{a}$ is the water consumption $(\mathrm{mm})$ during the whole growth period of Isatis indigotica. 
A

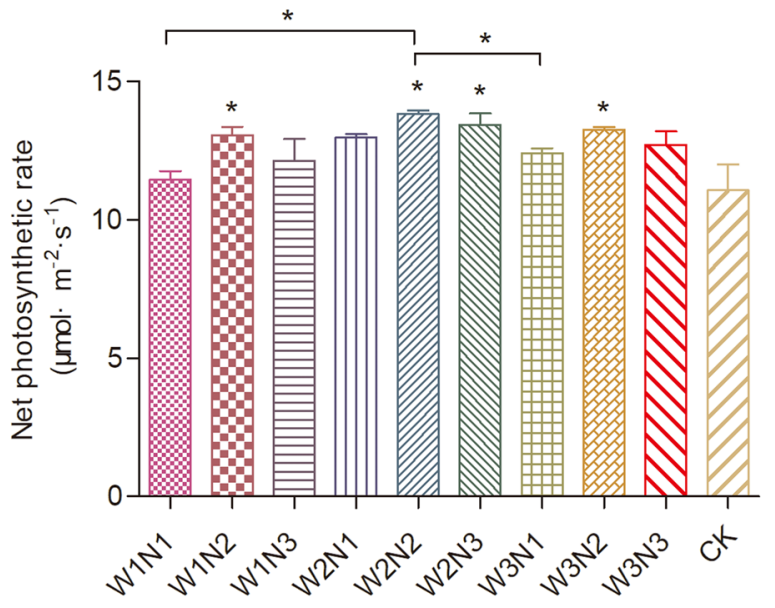

C

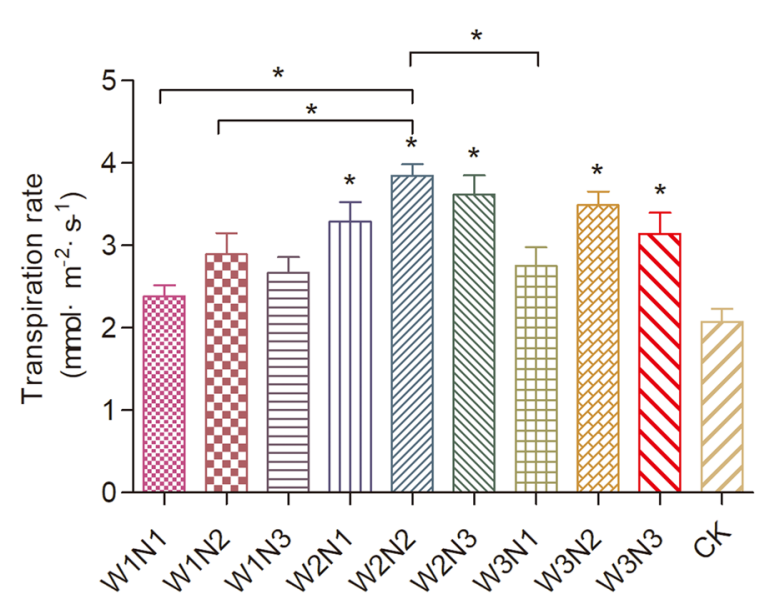

B

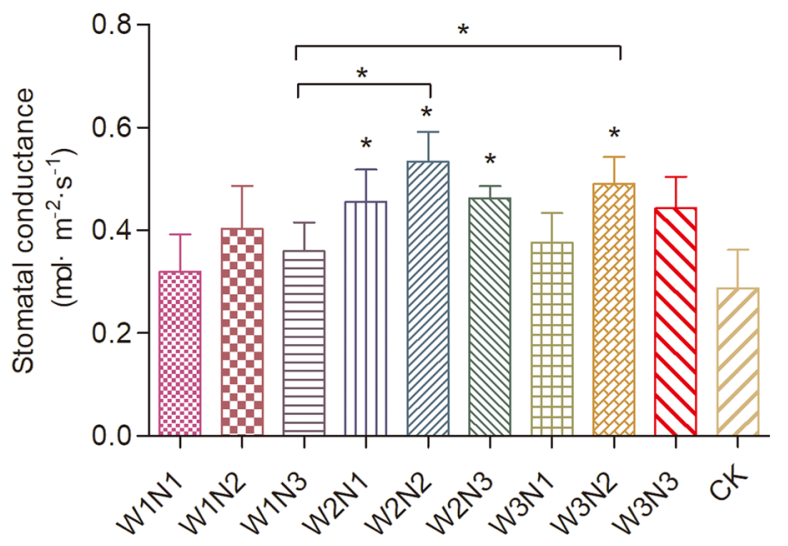

D

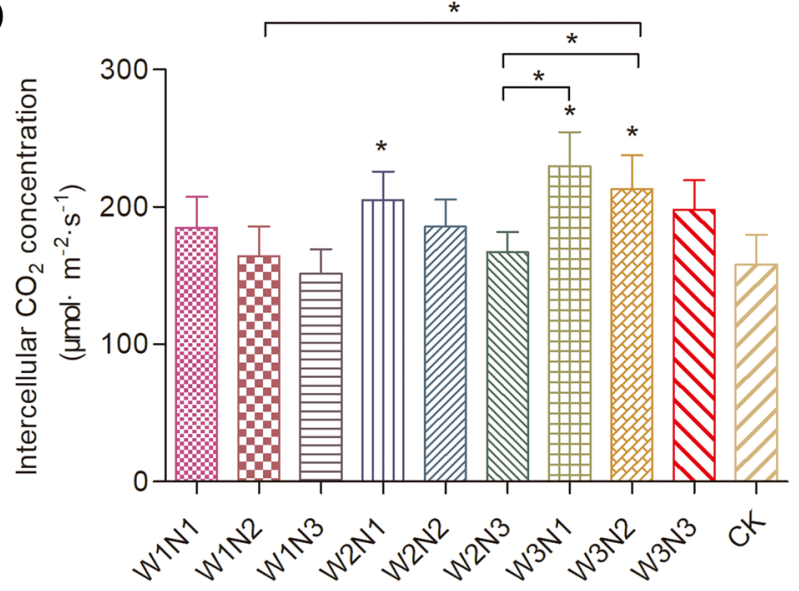

Figure 1. Photosynthetic characteristic values for Isatis indigotica in all treatments. The values shown are the mean $\pm S D, n=3$. Asterisks $\left({ }^{*}\right)$ indicate a significant difference at the $\mathrm{P} \leq 0.05$ level.

Quality. Determination of indigo, indirubin, and (R, S)-goitrin content was performed as follows: the Chinese Pharmacopoeia method ${ }^{12}$ was used to extract indigo, indirubin, and (R, S)-goitrin, and their contents were determined by high-performance liquid chromatography. The content of polysaccharide in Isatis indigotica root was determined by phenol-sulfuric acid colorimetry.

Statistical analysis. The data analyses were performed using SPSS software package (Version 21.0, IBM Corp., Armonk, NY). The significance of differences between treatments for the different measured parameters was evaluated using independent samples, followed by the Kruskal-Wallis test $(\mathrm{P} \leq 0.05)$. Figures 1,2 and 3 were all generated by GraphPad Prism software (5.0, GraphPad Software., San Diego, California). The data in each table were average values of three replicates.

\section{Results and discussion}

Photosynthetic characteristics. Water and nitrogen coupling treatment had a significant effect on the photosynthetic characteristics (Fig. 1). Generally, the net photosynthetic rates of the treatments were in the following order: CK, W1N1, W1N3, W3N1, W3N3, W2N1, W1N2, W3N2, W2N3, and W2N2. The treatments with low water and low nitrogen had significantly lower net photosynthetic rates than W2N2. The stomatal conductance and transpiration rate changed in similar patterns. The net photosynthetic rate showed a unimodal trend with the increase of nitrogen application at the same irrigation level. Under the same nitrogen application level, the net photosynthetic rate increased first and then decreased slowly with the increase of irrigation amount, with the highest photosynthetic rates in the order of $\mathrm{W} 2>\mathrm{W} 3>\mathrm{W} 1$. The net photosynthetic rate was the highest, with a mean value was $13.87 \mu \mathrm{mol} \mathrm{m}^{-2} \mathrm{~s}^{-1}$, in treatment $\mathrm{W} 2 \mathrm{~N} 2$. The results showed that severe water stress and excessive nitrogen were not conducive to the absorption and utilization of water and nutrients by crop roots, which led to the decrease of the photosynthetic rate. The effect of water and nitrogen treatment on the intercellular $\mathrm{CO}_{2}$ concentration was significant (Fig. 1). Under the condition of excessive water or nitrogen, the photosynthesis of Isatis indigotica decreased, and the intercellular $\mathrm{CO}_{2}$ concentration showed a trend opposite to that of the net photosynthetic rate.

Compared with N, P, and K deficiency treatments, water-N coupling could increase the Pn of crops, which was the same as that of other fruit trees and vegetables ${ }^{13}$. Accumulated photoassimilates in the third internode 

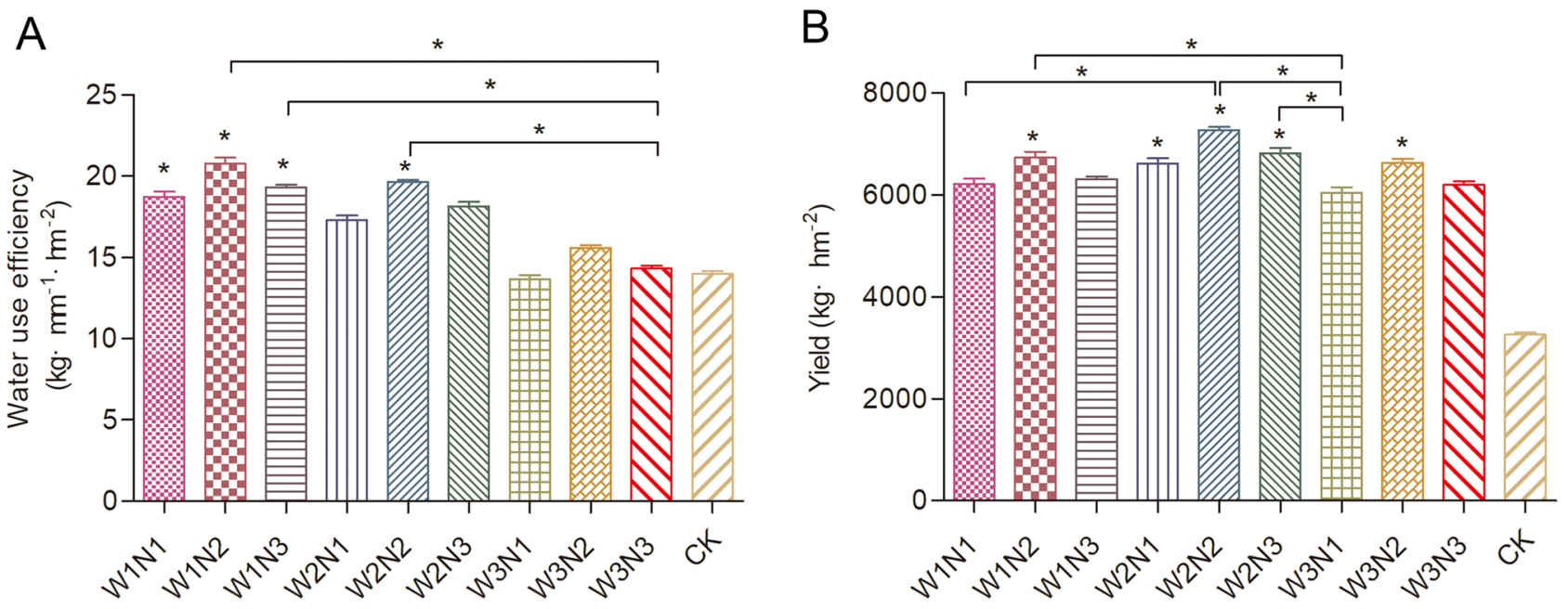

Figure 2. Yield and water use efficiency values for Isatis indigotica in all treatments. The values shown are the mean $\pm S D, n=3$. Asterisks ${ }^{*}$ ) indicate a significant difference at the $\mathrm{P} \leq 0.05$ level.

A

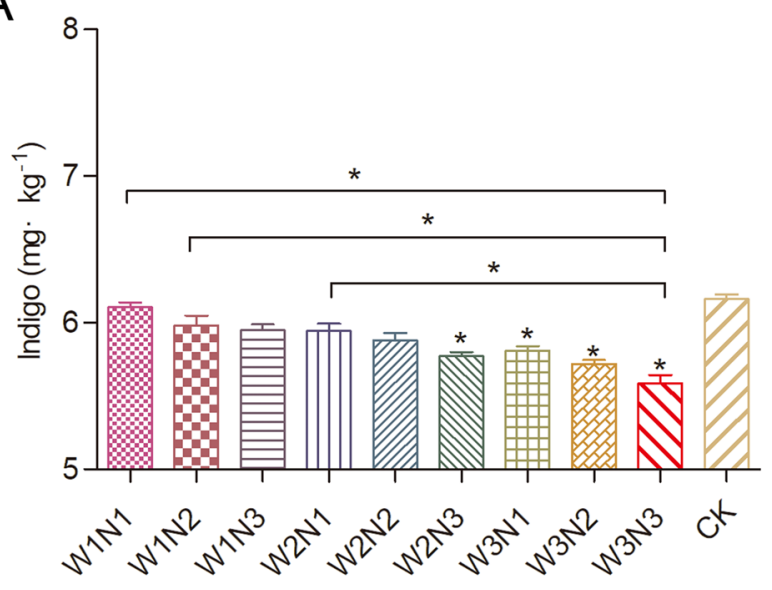

C

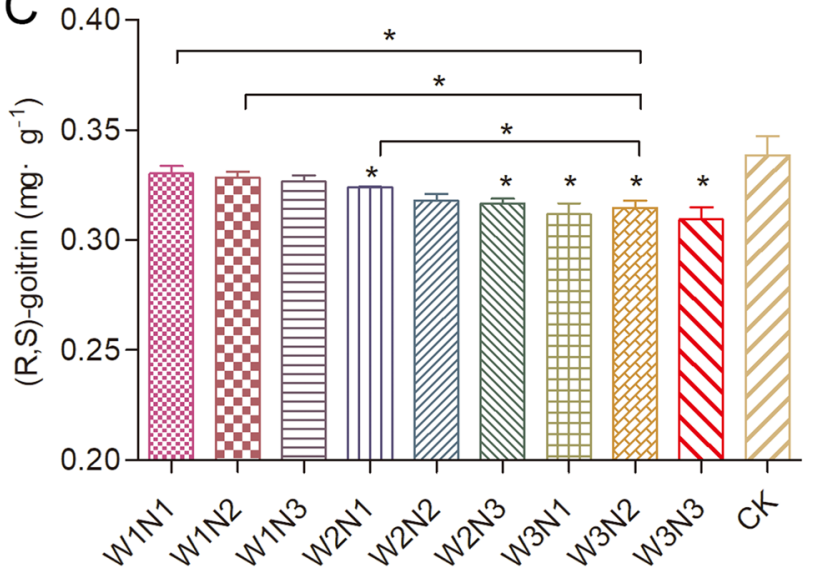

B

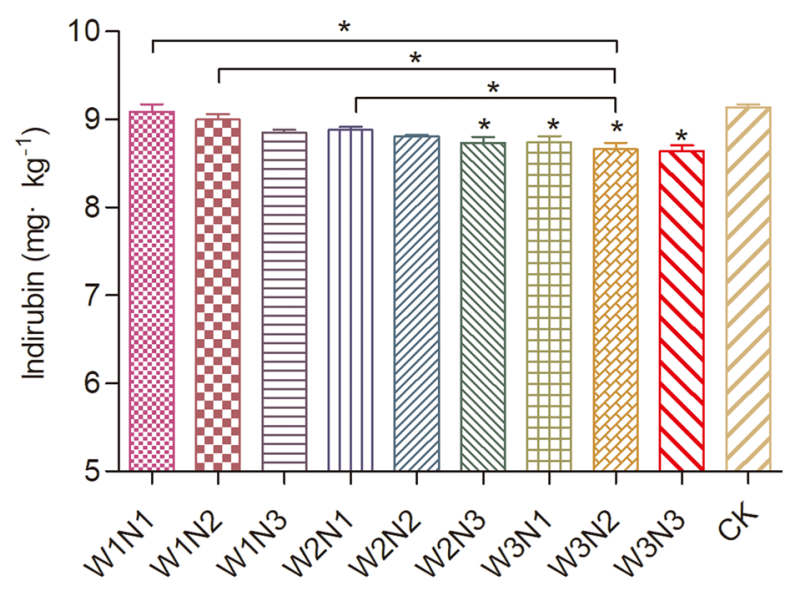

D

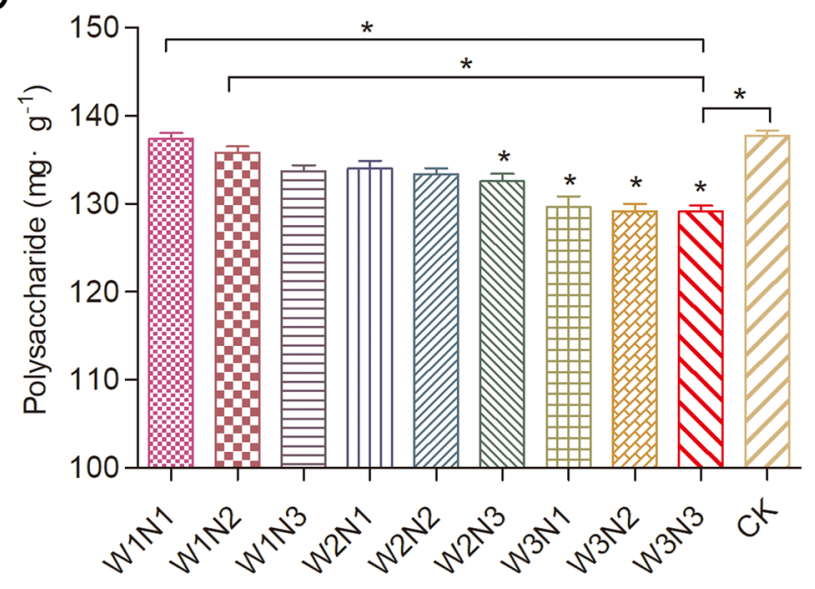

Figure 3. Quality values for Isatis indigotica in all treatments. The values shown are the mean $\pm S D, n=3$. Asterisks $\left.{ }^{*}\right)$ indicate a significant difference at the $\mathrm{P} \leq 0.05$ level. 
of the upper part of the main stems, as well as in the flag leaf sheath, are mobilized in a higher proportion and can contribute to grain filling in rice plants subjected to water stress in the tillering phase ${ }^{14}$. The Pn, Gs, and Tr of maize leaves at the seedling stage decreased significantly, while the $\mathrm{Ci}$ increased significantly when the nitrogen application rate was low ${ }^{15}$.

The experiments with Isatis indigotica demonstrate that the Pn, Gs, and Tr under the same irrigation level first increased and then decreased with the increase of the nitrogen application rate. The net photosynthetic rate, transpiration rate, and stomatal conductance of Isatis indigotica were improved by rational nitrogen application. Studies have reported similar findings in Isatis indigotica; with the decrease of N level, the net photosynthetic rate, transpiration rate, and stomatal conductance of leaves gradually decreased, while the intercellular $\mathrm{CO}_{2}$ concentration increased ${ }^{16,17}$. Under reasonable water and nitrogen coordination conditions, the synergistic effect of water and nitrogen increased, which effectively promoted the photosynthesis of Isatis indigotica. Under the condition of too much nitrogen or too little water, the antagonism of water and nitrogen was obvious, and the photosynthesis of Isatis indigotica was inhibited to a certain extent.

Yield and water use efficiency. The Isatis indigotica yield values presented are the average of two consecutive years of water-nitrogen trials (Fig. 2). The I. indigotica yields differed significantly between the waternitrogen treatments; the W2N2 and W2N3 treatments had the highest yields at 7277.5 and $6820.5 \mathrm{~kg} \mathrm{hm}^{-2}$, respectively. The lowest yield of $3264.5 \mathrm{~kg} \mathrm{hm}^{-2}$ was recorded in the control treatment. The yields of all treatments were significantly higher than that of the control treatment. The yields of the W2N2 and W2N3 treatments were significantly higher than those of the W1N1 and the W3N1 treatments. With the increase of the nitrogen application rate, the yield first increased and then decreased under the same irrigation conditions.

The water use efficiency values of Isatis indigotica presented are the average of 2 consecutive years of water-nitrogen trials (Fig. 2). The water use efficiency of Isatis indigotica differed significantly between the water-nitrogen treatments; the W1N2 and W2N2 treatments had the highest yields at 20.78 and $19.63 \mathrm{~kg} \mathrm{~mm}^{-1}$ $\mathrm{hm}^{-2}$, respectively. The lowest yield of $13.65 \mathrm{~kg} \mathrm{~mm}^{-1} \mathrm{hm}^{-2}$ was recorded in the W3N1 treatment. The water use efficiency values of the $\mathrm{W} 1 \mathrm{~N} 2$ and $\mathrm{W} 2 \mathrm{~N} 2$ treatments were significantly higher than that of the W3N3 treatment, which was the treatment with excess water and nitrogen fertilizer. The water use efficiency decreased with the increase of irrigation under the same nitrogen application conditions. The water use efficiency first increased and then decreased with the increase in nitrogen application rate under the same irrigation conditions. The W2N2 treatment had the highest yield and water use efficiency. Therefore, the water-nitrogen coupling mode of medium water and medium nitrogen application achieved the highest yield and effectively saved water. This was mainly due to the moderate water and nitrogen to promote the photosynthesis of Isatis indigotica and lead to more dry matter accumulation, so as to increase the yield.

Generally, appropriate water deficits can improve crop yield and water use efficiency ${ }^{18,19}$, and rational fertilization can increase crop yield, such as in fruit trees and vegetables ${ }^{20-22}$. The yield increase in the current experiment was probably related to reasonable water stress and reasonable nitrogen application; the W2N2 treatment had the highest yield and water use efficiency. However, excessive water and nitrogen reduced the yield and water use efficiency of Isatis indigotica. This was consistent with recent research reports ${ }^{23,24}$. Compared with the local flooding irrigation and excessive nitrogen fertilizer mode, the W2N2 treatment with moderate water and nitrogen application not only obtained a high yield but also significantly improved the water use efficiency. This method could reduce the effect of excessive water and fertilizer application on soil productivity and would be a better water and nitrogen management model for local Isatis indigotica production.

Quality. The Isatis indigotica quality values presented are the average of two consecutive years of waternitrogen trials (Fig. 3). These quality indicators mainly include the following content indicators: indigo, indirubin, (R, S)-goitrin, and polysaccharides. The Isatis indigotica quality indicators differed significantly between the water-nitrogen treatments. The CK treatment had the highest values of all quality indicators. Each quality indicator decreased gradually with the increase of water content under the same nitrogen application conditions. Each quality indicator decreased gradually with the increase of nitrogen application under the same water conditions. The (R, S)-goitrin content of the $\mathrm{W} 2 \mathrm{~N} 2$ treatment decreased by $6.5 \%$ compared with CK and by $3.9 \%$ compared with the W1N1 treatment.

Water is the medium for improving crop quality. Generally, the crop quality was improved by a suitable water deficit $^{25-27}$ and reasonable fertilization ${ }^{28-30}$. The quality of Isatis indigotica in the current experiment increased gradually with the decrease of water. The water deficit treatment increased the content of effective components and improved the quality of Isatis indigotica. The content of the effective components in all treatments reached the pharmacopoeia standard ${ }^{12}$. The quality indicator values of each treatment in the current experiment were significantly lower than those of the CK treatment, but there was little difference in the quality indicator values between each treatment. Moreover, the yield of the control treatment was much lower than that of other treatments. Therefore, the effective quality content of the control treatment was lower than other treatments. Excessive water and nitrogen inputs were not conducive to quality, which was not consistent with recent research reports ${ }^{31}$. Generally, the water-nitrogen coupling type of $\mathrm{W}_{2} \mathrm{~N}_{60}$ was antagonism basing on the average yield of winter wheat in the 10 years $^{32}$. Some scholars have studied the irrigation of jujube that WUE and ANUE of jujube cannot reach the maximum at the same time. Different ratio of water and nitrogen will produce coupling and antagonism ${ }^{33}$. The results showed that total $\mathrm{N}$ applications over $200 \mathrm{~kg} \mathrm{ha}^{-1}$ did not increase yield or quality. Water deficit treatment could be increased the content of effective components and improve the quality of Isatis indigotica. Due to the high evaporation, moderate water stress and effective use of nitrogen fertilizer, the active components of Isatis indigotica were easier to accumulate in its roots. The synergistic effect of water and nitrogen will lead to the accumulation of active components in Isatis indigotica. 


\section{Conclusions}

The findings of this study indicate that water-nitrogen coupling has distinct benefits. The Isatis indigotica yields differed significantly between the water-nitrogen treatments; the W2N2 and W2N3 treatments had the highest yields at 7277.5 and $6820.5 \mathrm{~kg} \mathrm{hm}^{-2}$, respectively. The W2N2 treatment of water and nitrogen at medium levels significantly promoted net photosynthetic rates and increased the yield and water use efficiency. However, the lack or excess of water and nitrogen would greatly reduce these benefits. Reasonable water stress had a significant positive impact on the quality of Isatis indigotica under the same nitrogen application conditions but no significant effect on the yield. The yield and quality of Isatis indigotica could be improved by reasonable water stress and moderate nitrogen application.

Received: 25 February 2021; Accepted: 12 August 2021

Published online: 30 August 2021

\section{References}

1. Sandhu, S. S. et al. Crop and water productivity of bed transplanted rice as influenced by various levels of nitrogen and irrigation in northwest India. Agric. Water Manage. 104, 32-39. https://doi.org/10.1016/j.agwat.2011.11.012 (2012).

2. Brueck, H. et al. Effects of $\mathrm{N}$ and water supply on water use-efficiency of a semiarid grassland in Inner Mongolia. Plant Soil 328, 495-505. https://doi.org/10.1007/s11104-009-0128-5 (2010).

3. Liu, X. et al. Optimization of water and fertilizer coupling system based on rice grain quality. Agric. Water Manage. 221, 34-46. https://doi.org/10.1016/j.agwat.2019.04.009 (2019).

4. Li, H. H., Liu, H., Pang, J., Li, S. \& Sun, J. S. Effects of water and nitrogen interaction on growth and nutrient accumulation of potted tomatoes. Trans. Chin. Soc. Agric. Mach. 50, 272-279. https://doi.org/10.6041/j.issn.1000-1298.2019.09.032 (2019).

5. Sui, R., Byler, R. K., Fisher, D. K., Barnes, E. M. \& Delhom, C. D. Effect of supplemental irrigation and graded levels of nitrogen on cotton yield and quality. J. Agric. Sci. 6, 119-131. https://doi.org/10.5539/jas.v6n2p119 (2014).

6. Fiasconaro, M. L. et al. Effects of nitrogen source and water availability on stem carbohydrates and cellulosic bioethanol traits of alfalfa plants. Plant Sci. 191-192, 16-23. https://doi.org/10.1016/j.plantsci.2012.04.007 (2012).

7. Gholamhoseini, M., Aghaalikhani, M., Sanavy, S. M. \& Mirlatifi, S. M. Interactions of irrigation, weed and nitrogen on corn yield, nitrogen use efficiency and nitrate leaching. Agric. Water Manage. 126, 9-18. https://doi.org/10.1016/j.agwat.2013.05.002 (2013).

8. Miller, J. et al. Influence of crop residues and nitrogen fertilizer on soil water repellency and soil hydrophobicity under long-term no-till. Can. J. Soil Sci. 99, 334-344. https://doi.org/10.1139/CJSS-2019-0003 (2019).

9. Li, W. M., Shi, J. L., Han, H. S., Zhang, M. H. \& Dong, Z. T. Effects of water saving irrigation schedule on water consumption and yield of Isatis indigotica root. J. Irrig. Drain. 26, 106-109. https://doi.org/10.13522/j.cnki.ggps.2007.06.016 (2007).

10. Deng, H. L. et al. Responses of growth, photosynthetic characteristics and quality Isatis in Hexi corridor mulched drip irrigation under water deficit. J. Soil Water Conserv. 32, 321-327. https://doi.org/10.13870/j.cnki.stbcxb.2018.03.048 (2018).

11. Pan, S. et al. Effects of nitrogen and shading on root morphologies, nutrient accumulation, and photosynthetic parameters in different rice genotypes. Sci. Rep. 6, 32148. https://doi.org/10.1038/srep32148 (2016).

12. National Pharmacopoeia Committee, Chinese Pharmacopoeia Commission. China Medical Science and Technology Press (2015).

13. Efthimiadou, A., Bilalis, D., Karkanis, A. \& Froud-Williams, B. Combined organic/inorganic fertilization enhance soil quality and increased yield, photosynthesis and sustainability of sweet maize crop. Aust. J. Crop. Sci. 4, 722-729. https://doi.org/10.2134/agron j2010.0122 (2010).

14. García, A., Dorado, M., Pérez, I. \& Montilla, E. Effect of water deficit on the distribution of photoassimilates in rice plants (Orysa sativa L.). Interciencia 35, 47-54 (2010).

15. Li, Q. et al. Effects of low nitrogen stress on photosynthetic characteristics and chlorophyll fluorescence parameters of maize cultivars tolerant to low nitrogen stress at the seedling stage. J. Plant Nutr. Fertil. 21, 1132-1141. https://doi.org/10.11674/zwyf. 2015.0505 (2015).

16. Guan, J. L. et al. Effects of nitrogen nutrition on the growth and active components of Isatis indigotica Fort. Seedlings. Chin. J. Ecol. 37, 106-113. https://doi.org/10.13292/j.1000-4890.201808.030 (2018).

17. Farquhar, G. D., Caemmerer, S. V. \& Berry, J. A. Models of photosynthesis. Plant Physiol. 125, 42-45. https://doi.org/10.1104/pp. 125.1.42 (2001).

18. Kifle, M. \& Gebretsadikan, T. G. Yield and water use efficiency of furrow irrigated potato under regulated deficit irrigation, AtsibiWemberta, North Ethiopia. Agric. Water Manage. 170, 133-139. https://doi.org/10.1016/j.agwat.2016.01.003 (2016).

19. Bakhsh, A., Hussein, F., Ahmad, N., Hassan, A. \& Farid, H. U. Modeling deficit irrigation effects on maize to improve water use efficiency. Pak. J. Agric. Sci. 49, 331-341. https://doi.org/10.1021/jf303572y (2012).

20. Li, S. et al. Rational trade-offs between yield increase and fertilizer inputs are essential for sustainable intensification: A case study in wheat-maize cropping systems in China. Sci. Total Environ. 679, 328-336. https://doi.org/10.1016/j.scitotenv.2019.05.085 (2019).

21. Liu, Q. et al. Effects of different fertilization regimes on crop yield and soil water use efficiency of millet and soybean. Sustainability 12, 4125. https://doi.org/10.3390/su12104125 (2020).

22. Zhang, M. H. et al. Effects of combined organic/inorganic fertilizer application on growth, photosynthetic characteristics, yield and fruit quality of Actinidia chinesis cv 'hongyang. Glob. Ecol. Conserv. 22, e00997. https://doi.org/10.1016/j.gecco.2020.e00997 (2020).

23. Dalla, C. L. \& Gianquinto, G. Water stress and watertable depth influence yield, water use efficiency, and nitrogen recovery in bell pepper: lysimeter studies. Aust. J. Agric. Res. 53, 201-210. https://doi.org/10.1071/AR00133 (2002).

24. Zotarelli, L., Scholberg, J. M., Dukes, M. D., Muñoz-Carpena, R. \& Icerman, J. Tomato yield, biomass accumulation, root distribution and irrigation water use efficiency on a sandy soil, as affected by nitrogen rate and irrigation scheduling. Agric. Water Manage. 96, 23-34. https://doi.org/10.1016/j.agwat.2008.06.007 (2009).

25. Hussain, M. et al. Exogenous glycinebetaine and salicylic acid application improves water relations, allometry and quality of hybrid sunflower under water deficit conditions. J. Agron. Crop. Sci. 195, 98-109. https://doi.org/10.1111/j.1439-037X.2008.00354.x (2010).

26. Nangare, D. D., Singh, Y., Kumar, P. S. \& Minhas, P. S. Growth, fruit yield and quality of tomato (lycopersicon esculentum Mill.) as affected by deficit irrigation regulated on phenological basis. Agric. Water Manage. 171, 73-79. https://doi.org/10.1016/j.agwat. 2016.03.016 (2016).

27. Yang, H. et al. Improved water use efficiency and fruit quality of greenhouse crops under regulated deficit irrigation in northwest China. Agric. Water Manage. 179, 193-204. https://doi.org/10.1016/j.agwat.2016.05.029 (2016).

28. Gianquinto, G., Fecondini, M., Mezzetti, M. \& Orsini, F. Steering nitrogen fertilisation by means of portable chlorophyll meter reduces nitrogen input and improves quality of fertigated cantaloupe (Cucumis melo L. var. cantalupensis Naud.). J. Sci. Food Agric. 90, 482. https://doi.org/10.1002/jsfa.3843 (2010).

29. Stevens, W. B., Sainju, U. M., Thecan, C. T. \& Iversen, W. M. Malt barley yield and quality affected by irrigation, tillage, crop rotation, and nitrogen fertilization. Agron. J. 107, 2107-2119. https://doi.org/10.2134/agronj15.0027 (2014). 
30. Wang, Z. H., Li, S. X. \& Malhi, S. Effects of fertilization and other agronomic measures on nutritional quality of crops. J. Sci. Food Agric. 88, 7-23. https://doi.org/10.1002/jsfa.3084(2010) (2010).

31. Rens, L. R. et al. Biomass accumulation, marketable yield, and quality of atlantic Potato in response to nitrogen. Agron. J. 107, 931. https://doi.org/10.2134/agronj14.0408 (2015).

32. Zhang, J. T. et al. A novel method for quantitating water and fertilizer coupling types and its application in optimizing water and nitrogen combination in winter wheat in the north China plain. Sci. Agric. Sin. 52, 2997-3007. https://doi.org/10.3864/j.issn. 0578-1752.2019.17.008 (2019).

33. Dai, Z. G. et al. Coupling effects of irrigation and nitrogen levels on yield, water and nitrogen use efficiency of surge-root irrigated jujube in a semiarid region. Agric. Water Manage. 213, 146-154. https://doi.org/10.1016/j.agwat.2018.09.035 (2019).

\section{Acknowledgements}

This study was supported by the Key Research and Planning Projects of Gansu Province (No. 18YF1NA073), the Innovation Capacity Improvement Project of Colleges and Universities of Gansu (No. 2019B-075), and the Youth Science and Technology Foundation of Gansu (No. 20JR5RA003).

\section{Author contributions}

Y.W., X.H., F.L. and H.D. wrote the main manuscript text and Z.W., C.H. and Y.H. prepared Figs. 1, 2 and 3 and Y.B., L.L. and C.Z. provided the test site. All authors reviewed the manuscript.

\section{Competing interests}

The authors declare no competing interests.

\section{Additional information}

Correspondence and requests for materials should be addressed to Y.W.

Reprints and permissions information is available at www.nature.com/reprints.

Publisher's note Springer Nature remains neutral with regard to jurisdictional claims in published maps and institutional affiliations.

(c) (i) Open Access This article is licensed under a Creative Commons Attribution 4.0 International License, which permits use, sharing, adaptation, distribution and reproduction in any medium or format, as long as you give appropriate credit to the original author(s) and the source, provide a link to the Creative Commons licence, and indicate if changes were made. The images or other third party material in this article are included in the article's Creative Commons licence, unless indicated otherwise in a credit line to the material. If material is not included in the article's Creative Commons licence and your intended use is not permitted by statutory regulation or exceeds the permitted use, you will need to obtain permission directly from the copyright holder. To view a copy of this licence, visit http://creativecommons.org/licenses/by/4.0/.

(C) The Author(s) 2021 